\title{
Analysis on Investment and Financial Problems of the Elderly in Jinan City
}

\author{
Qi Zhong, Qian Zhang, and Kaiyue Xu \\ Qilu Normal University, Lishan Road, Jinan, China \\ zhongqi@bk.ru, zhang17111@yeah.net,xu_kaiyue@yeah.net
}

Keywords: Elderly, Jinan, Investment

\begin{abstract}
With the growing aging population, the elderly has become an important group to participate in investment and financing in Jinan City, Shandong Province. Due to their psychological and physiological differences, there exist some problems in the process of investment and financing inevitably. By investigating the present situation of Jinan investment and financing market, this paper analyses the problems arising from the investment and financing process of the elderly, puts forward reasonable countermeasures and suggestions to the existing problems, provides guidance for the choice of financial products for the elderly in Jinan City, and offers help for enterprises to develop new products as well.
\end{abstract}

\section{INCOME STATUS OF THE ELDERLY IN JINAN CITY}

With the yearly increase of the income level of Chinese, personal financial needs are exploding. In contemporary China, financial management becomes a fashion. The age structure of the financial planner has changed, that means the proportion of the elderly is increasing. There is no unified standard for the division of "the elderly" internationally, but most western countries refer to those over the age of 65 as the elderly. In contrast to the developed countries, the Article II of the Law on Protection of Rights and Interests of the Elderly of the People's Republic of China clearly stipulates: “The elderly mentioned in this Law refer to the citizens over 60 years old." (Standing Committee of the National People's Congress, 2015).

The United Nations also clearly stipulates the ageing population: When the aged population over 65 years old accounts for $7 \%$ of the total population, or the aged population over 60 years old accounts for $10 \%$ of the total population, it is considered that the society has entered an ageing society. According to the data of Shandong Statistics Department in recent years, the aged population over 65 years old reaches 4,197,000 in 1982, which accounts for $5.6 \%$ of the total population in Shandong Province. The aged population over 65 years old reaches 13,079,800 in 2016, which accounts for $13.2 \%$ of the total population in Shandong Province. The data show the upward trend of the aged population year by year and indicate that Shandong Province has entered the stage of rapid development of aging population. As the capital of Shandong Province, the number of aged population over 60 years old in Jinan City reaches 1,288,000, which accounts for an increasing proportion of the total population. Therefore, it is of great practical significance to help the elderly to manage their finances, analyse the investment and financing problems of the elderly in Jinan City.

In 2014, the annual per capita income of the elderly in Shandong Province is 15,217 RMB, with the monthly average of 1,268 RMB. In 2016, the average wage of urban non-private employees in Shandong Province ranks $11^{\text {th }}$ in China, with the average wage of 62,539 RMB. The average wage of employees in Jinan City is 63,996 RMB, which is slightly higher than the average wage in the province. The wage level takes the leading position in the ranks of the national average wage (Shandong Provincial Bureau of Statistics, 2017).

\section{REASONS FOR FINANCIAL MANAGEMENT OF THE ELDERLY IN JINAN CITY}

Firstly, based on the analysis of the elderly's income status in Shandong Province, the conclusion is drawn that the elderly in Jinan City have better financial foundation than other cities 
in Shandong Province. Secondly, the elderly in Jinan City have much more contact with the outside world and yearn for a better life. That's the reason they have financial needs. Thirdly, the stimulation of the investment market encourages the elderly in Jinan City to have financial incentive (Cai, P., 2014).

From the beginning of 2011 to the end of 2016, the urban and rural resident basic pension in Jinan City consecutively increases for six years. Although the increasing amount is small, the growth trend of basic pension imperceptibly influences some elderly's psychologies. This kind of psychology stimulates the elderly's consumption including financial products.

On the other hand, the increasing of elderly university improves the cultural knowledge of some elderly. The overall education level of the elderly has upgraded. They begin to understand and accept financial management. With the time increase after retirement and the quick decrease of income, most aged families need financing to make up for the income. Therefore, the number of elderly is growing rapidly among the financial planners in Jinan City.

\section{THE ELDERLY'S PROBLEMS IN FINANCIAL MARKET IN JINAN CITY}

There are many kinds of financial products in Jinan financial market. There are many options for the elderly as well. Most of them would choose deposit, foreign exchange, bank financial products, bond, fund, stock, futures and other forms of financial products. Due to the age characteristics, there exist various problems of the elderly in choosing financial products during the process. These problems could be divided into subjective aspect and objective aspect.

\subsection{Subjective Financial Problems of the Elderly}

The elderly's subjective knowledge of financial management is insufficient. There are many kinds of financial products with different risks in Jinan financial market. The elderly have insufficient understanding of the properties, prospective return and potential losses of financial products. According to the social survey, the elderly lack the subjective knowledge about the risk of various financial products generally. Their financial choices are mainly based on the planning and recommendation of financial managers. Because of the lack of subjective knowledge about financial products, the elderly are easily cheated during the choice of financial products.

The elderly's choice of financial management is improper. Because of the decline in physiological function and dopamine levels in the brain, the elderly are generally reluctant to take high risks of financial products. They are conservative during the selection process. According to the bank staffs' statistics, the majority of elderly with active investment would choose moderate financial products in Jinan City. This type of financial planners is supposed to choose the financial products or investment vehicles with capital preservation and upside potential. Some of the elderly pursue the profits while ignore the risks, or even mistakenly equate the prospective returns in the financial products propagation with the actual return.

\subsection{Objective Financial Environment Problems}

There lacks the specially-designed financial products for the elderly. Most financial products are designed for young and middle-aged people. Most of them are recommended for citizens from the age of 18 to 59 which ignores the needs of the elderly. According to the survey, all kinds of financial products from Agricultural Bank of China, Industrial and Commercial Bank of China, Qilu Bank, Bank of Qingdao and other enterprises don't have the specially-designed financial products for the elderly. The elderly's financial needs could not be fully met in Jinan City.

There lacks the financial information for the elderly. On August $28^{\text {th }} 2017$, Industrial and Commercial Bank of China held the first "ICBC Financial Festival” in the nationwide. At the same time, in order to realize their own developments, all major banks and financial institutions in Jinan City went with the tide and arranged some activities. From observation, the number of the elderly is relatively small in these major banks. They lacks the enthusiasm about advisory as well. It indicates that the elderly's financial awareness is still weak and they are not sensitive to financial products. Not only is the bank financial products propagation not in place, but also the promotion of investment products in other investment markets for the elderly is very limited. 


\section{COUNTERMEASURES FOR THE FINANCIAL PROBLEMS OF THE ELDERLY IN JINAN CITY}

The elderly should purchase financial products in the places with sound reputation, such as banks. When purchase financial products from normal channels, the salesperson would repeat the risk of products. For example, before purchasing financial products from the major banks in Jinan City, the first-purchase customers will be asked to fill in the Assessment Questionnaire of Customer's Risk Tolerance. The process would be caught on video. The managers will determine the type of investors based on the results of questionnaire, and recommend products that are in line with the types. Certainly, the major banks should also reinforce the management and propagate the financial risks properly. Other institutions should not evade the risks when recommend the financial products to the elderly.

The elderly should rationally optimize the financial plan. In view of the special financial psychology of elder investors, deposit, monetary fund and bank financial products with capital preservation are more suitable for them. From the comparison of Table 1, the profit of certificate deposits are higher, and is the best choice for the elderly in Jinan City. The recovery period of real estate investment is more than 2 years or even longer and the investment amount is huge, which is difficult for the elderly to accept. The age at issue of all types of financial insurance covers from 18 to 59 years old. The elderly cannot insure for themselves. With the growing of age, the cash value growth rate of financial insurance is decreasing. It is not worth insuring. Moreover, since the variable change and huge investment risk of stock, gold, fund and foreign exchange, it is not recommended to purchase them for the elderly. The financial plan of the elderly's investment should be optimized rationally according to their own conditions.

Table 1: The Deposit Rate of Qilu Bank in October 2017.

\begin{tabular}{|c|c|c|}
\hline Duration of Deposit & $\begin{array}{c}\text { The Ordinary Time } \\
\text { Deposit Rate }\end{array}$ & $\begin{array}{c}\text { The Time Deposit Rate of More Than } \\
\text { 200,000 RMB }\end{array}$ \\
\hline Semiannual & $1.625 \%$ & $1.850 \%$ \\
\hline One Year & $1.875 \%$ & $2.130 \%$ \\
\hline Two Years. & $2.520 \%$ & $2.980 \%$ \\
\hline
\end{tabular}

Enterprises should provide specifically-designed financial products for the elderly. The subdivision of enterprise products is helpful to better meet the customers' needs. The characteristics of elder investors are different from young and middle-aged investors. They have poor psychological enduring capacity and physical strength when compared with young people. In the life cycle of the family, the aged family in the period of retirement is characterized with weak risk tolerance and low prospective returns. They often choose conservative investment. Their financial objective is enjoying life. Products that meet these needs are to be designed. The citizens over 60 years old with Jinan registration accounts for $20 \%$ of the total population in the city. There still exists large market. The market prospect of specifically-designed financial products for the elderly is very promising.

Enterprises should promote the financial propagation for the elderly. The purchase of financial products is a complex decision for the elderly. When they make decisions, they will purchase the financial products after fully understand the information. The method of advertising exploration could be used in financial markets to promote financial products. This method not only collects market information and facilitates transactions, but also achieve the goal of helping the elderly with financial management (An, J., 2016).

\section{CONCLUSIONS}

In conclusion, in the course of investigation and analysis, it is found that the elderly who accounts for $20 \%$ of the total population in Jinan City, have a good source of income and a certain degree of cultural accomplishment to meet the basic conditions of investment and financing. However, there lacks the specifically-designed products and products promotion for the elder 
customers in Jinan financial market. The elderly lacks the knowledge and experience of financing. The common improvement of design and publicity of the products between enterprises and elder customers is conducive to the healthy development of the elder financial market in Jinan City.

\section{ACKNOWLEDGEMENTS}

This study is funded by The Optimization Selection of the Elderly's Moderate Financial Management (2017W0705) which belongs to the Young Teacher Scientific Research Fund Project of Qilu Normal University.

\section{REFERENCES}

[1] An, J., 2016. Family Financial Planning, Tsinghua University Press. Beijing, 1st edition.

[2] Cai, P., 2014. The Dilemma and the Thinking on Postponing Retirement, Journal of Qilu Normal University. 6(29), pp.86-91.

[3] Shandong Provincial Bureau of Statistics, 2017. Shandong Statistical Yearbook 2017, China Statistics Press. Beijing, 1st edition.

[4] Standing Committee of the National People's Congress, 2015. Law of the People's Republic of China on the Protection of the Rights and Interests of the Elderly (2015 Amendment), China Democracy and Legal System publishing House. Beijing, 1st edition. 